\title{
Successful endoscopic treatment of severe ischemic damage of the bronchus
}

\author{
Antonio D’ Andrilli, MD, ${ }^{a}$ Claudio Andreetti, MD, ${ }^{\mathrm{a}}$ Cecilia Menna, MD, ${ }^{\mathrm{a}}$ and Erino A. Rendina, MD,, ,b \\ Rome, Italy
}

\author{
From the 'Department of Thoracic Surgery, Sant'Andrea Hospital, Sapienza University, and ${ }^{\text {b Lorillard Spencer }}$ \\ Cenci Foundation, Rome, Italy. \\ Disclosures: Authors have nothing to disclose with regard to commercial support. \\ Received for publication Oct 31, 2016; revisions received Dec 30, 2016; accepted for publication Feb 20, 2017; \\ available ahead of print April 5, 2017. \\ Address for reprints: Antonio D’Andrilli, MD, Department of Thoracic Surgery, Sant'Andrea Hospital, Via di \\ Grottarossa 1035, Rome 00189, Italy (E-mail: adandrilli@ hotmail.com). \\ J Thorac Cardiovasc Surg 2017;154:e17-9 \\ $0022-5223 / \$ 36.00$ \\ Copyright (C) 2017 by The American Association for Thoracic Surgery \\ http://dx.doi.org/10.1016/j.jtcvs.2017.02.057
}

Video clip is available online.

Endoscopic techniques have been reported as viable options for the treatment of small ischemic bronchial dehiscence after major lung resection. ${ }^{1-4}$ Extended necrotic lesions $(>1 \mathrm{~cm})$ may represent life-threatening complications that often require reoperation for surgical repair, including completion pneumonectomy and vascularized flap transposition.

We report the case of a patient with severe ischemic bronchial damage after bilobectomy who underwent successful, completely endoscopic treatment.

\section{CLINICAL SUMMARY}

A 60-year-old woman underwent middle-lower bilobectomy with hilar and mediastinal lymphadenectomy (station 2, 4, 7, 8, 9, 10, and 11) and staple bronchial closure after neoadjuvant chemoradiotherapy (50 Gy) for T3 N2 right lung adenocarcinoma. Sudden appearance of air leak on postoperative day 9 led to flexible bronchoscopy showing a 3-mm dehiscence of the bronchial stump. Bronchoscopy on postoperative day 11 confirmed the dehiscence of the bronchial stump and showed an additional $2.5-\mathrm{cm}$ ischemic defect of the right main bronchus posterior wall (Figure 1, $A$ and $C$ ). Through rigid bronchoscopy, closure of the bronchial stump dehiscence was performed with an Amplatzer Atrial Septal Occluder (5-mm waist diameter) (St Jude Medical, St Paul, Minn) (Figure 1, B). Closure of the ischemic posterior bronchial defect was obtained with the placement of a fully covered self-expanding metallic stent (Tracheobronxane Silmet; Boston Scientific Corp, Marlborough, Mass) (conical 22-16 L, 50/50 mm) (Figure 1, D) with its upper limit in the lower trachea and its distal end in the

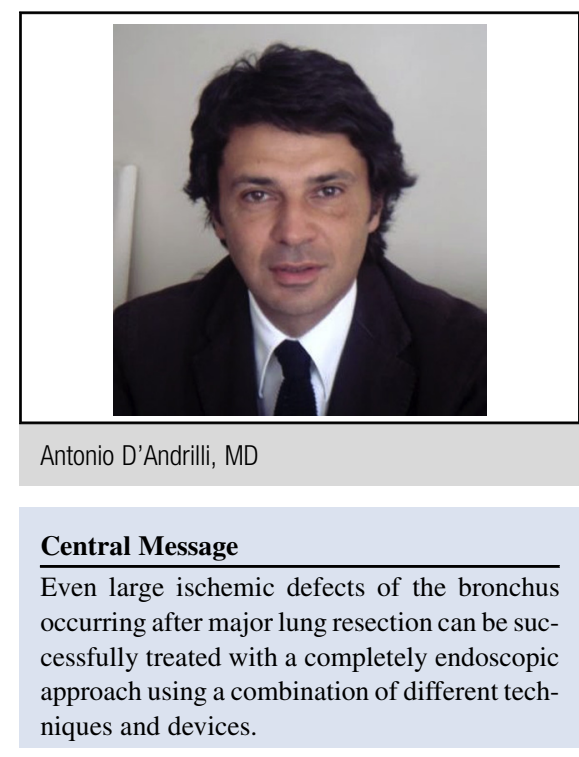

See Editorial Commentary page e 21 .

bronchus intermedius. The stent was fixed to the bronchial wall with 5-mm helical titanium tacks to avoid dislocation, as previously reported. ${ }^{2}$ Ventilation of the residual right lung was obtained by the neodymium-doped yttriumaluminum-perovskite laser ablation of the stent polyester cover at the level of the right upper lobe bronchus orifice. Ablation of the polyester cover was also performed at the medial aspect of the stent upper limit to optimize the ventilation of the left main bronchus. Safety of this laser ablation has been reported in a previous article. ${ }^{5}$ Immediate resolution of the bronchopleural fistula (BPF) was achieved after the endoscopic procedure with air leak cessation and progressive residual right lung re-expansion. Daily pleural cavity irrigation with antibiotic solution based on microbiological findings was performed until sterilization of the pleural fluid. Chest radiograph (Figure 2, A) and computed tomography scan performed during postoperative hospitalization showed the self-expanding stent in place with complete patency of the left main bronchus and right upper lobe bronchus (Video 1). The patient was discharged on postoperative day 31 with the chest tube in place connected to Heimlich valve due to incomplete lung re-expansion. Drain removal was on postoperative day 49 after complete right lung re-expansion. Uneventful removal of the stent was possible 3 months after placement showing complete healing of the posterior 


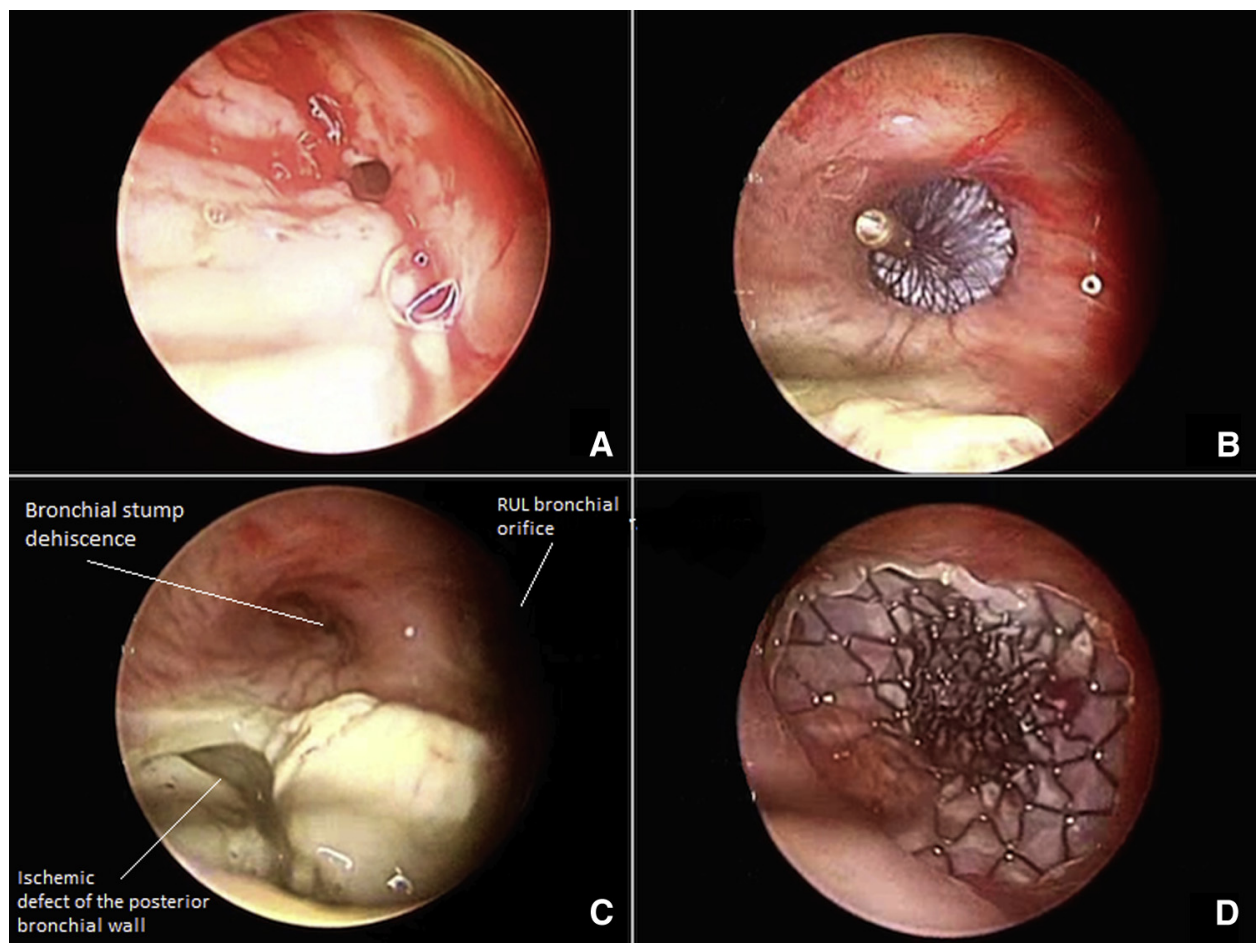

FIGURE 1. Endoscopic view. A, Dehiscence of the bronchial stump before bronchoscopic closure. B, After bronchoscopic closure (Amplatzer Septal Occluder [St Jude Medical, St Paul, Minn]). C, Large defect of the right main bronchus posterior wall before closure. D, After bronchoscopic closure (stent).

bronchial wall with the Amplatzer occluder in place at the level of the bronchial stump (Video 1). The patient is alive and in good general condition 1 year after stent removal with complete recovery of the bronchial damage (Figure 2, $B$ ).

\section{DISCUSSION}

A number of endoscopic techniques have been proposed to close BPF, including the application of different products (fibrin and acrylic glues, demineralized human donor spongiosa, and sclerosant agents), but none of these has been able to provide high success rate for fistulas larger than $5 \mathrm{~mm} .{ }^{1}$ Experiences with devices that allow occlusion of the bronchial stump dehiscence using endoscopic approaches have shown a significant increase in the probability of obtaining permanent fistula closure. The endobronchial use of the Amplatzer occluder, a device generally employed for endovascular treatment of interatrial defect, has been shown to be among the most reliable option in this setting. ${ }^{3}$

The use of airway stents has been reported, principally for postpneumonectomy BPF with variable efficacy. ${ }^{2,4} \mathrm{We}$ have reported the successful use of conical, fully covered self-expandable metallic stent to achieve total exclusion of the fistula in a variety of situations related to ischemic

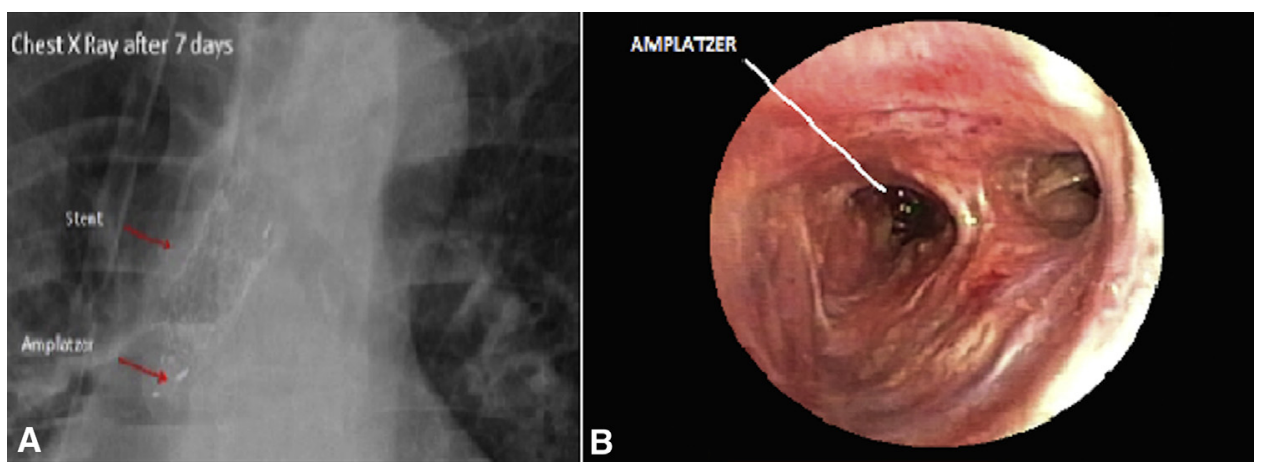

FIGURE 2. A, Chest radiograph showing the stent and the Amplatzer device. B, Bronchoscopic check 1 year after stent removal showing complete recovery of the bronchial wall with the Amplatzer Septal Occluder (St Jude Medical, St Paul, Minn) in place at the level of the bronchial stump. 


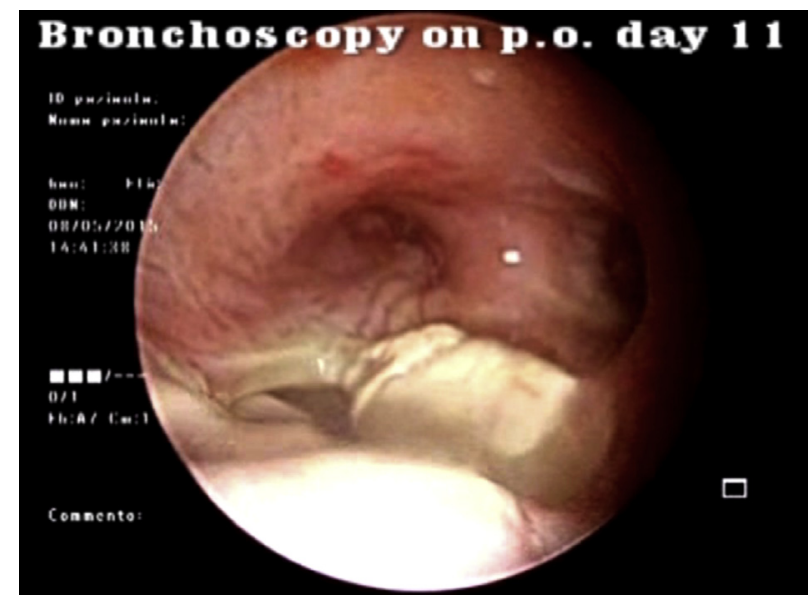

VIDEO 1. Bronchoscopy on postoperative day 11 shows a large ischemic defect of the posterior wall of the right main bronchus associated with a 3$\mathrm{mm}$ dehiscence of the bronchial stump after middle-lower bilobectomy. Through rigid bronchoscopy, bronchial stump dehiscence occlusion is obtained with an Amplatzer occluder (St Jude Medical, St Paul, Minn). Closure of the large posterior bronchial defect is achieved with a covered, self-expanding stent fixed to the bronchial wall with helical titanium tacks. neodymium-doped yttrium-aluminum-perovskite laser ablation of the polyester cover is performed at the medial aspect of the stent upper limit to optimize ventilation of the left main bronchus and at the orifice of the right upper lobe bronchus to allow ventilation of the residual right lung. Chest radiograph and computed tomography scan performed during postoperative hospitalization show the self-expanding stent in place with complete patency of the left main bronchus and the right upper lobe bronchus, and the Amplatzer occluder at the level of the bronchial stump. Uneventful removal of the stent was performed 3 months after placement showing complete healing of the posterior bronchial wall. Bronchoscopic control after 2 months and computed tomography control after 6 months are reported. Video available at: http://www.jtcvsonline.org/article/S0022-5223(17) 30419-1/addons.

damage of the bronchus, either after pneumonectomy or after lobectomy. ${ }^{2}$

To the best of our knowledge, this case is the first describing the combined use of an Amplatzer occluder and conical covered self-expandable stent allowing the successful treatment of a bronchial stump dehiscence concurrent with a large defect of the main bronchus, avoiding further surgical operations. The presence of residual lung in this patient certainly helped the bronchial wall recovery after the fistula exclusion because of apposition of healthy tissue to the ischemic bronchus. Success of the endoscopic treatment is principally related to the possibility of obtaining complete, rapid, and stable occlusion of the fistula. If this is not feasible, reoperation is indicated.

\section{CONCLUSIONS}

Even extended ischemic defects of the bronchus occurring after major lung resection can be successfully treated with a completely endoscopic approach. Different techniques and devices can be used and associated according to the fistula characteristics, allowing increased therapeutic efficacy.

The authors thank Dr Marta Silvi for providing data management and editorial work

\section{References}

1. Andreetti C, D'Andrilli A, Ibrahim M, Poggi C, Maurizi G, Vecchione A, et al Submucosal injection of the silver-human albumin complex for the treatment of bronchopleural fistula. Eur J Cardiothorac Surg. 2010;37:40-3.

2. Andreetti C, D’Andrilli A, Ibrahim M, Ciccone AM, Maurizi G, Mattia A, et al Effective treatment of post-pneumonectomy bronchopleural fistula by conical fully covered self-expandable stent. Interact Cardiovasc Thorac Surg. 2012;14: 420-3.

3. Kramer MR, Peled N, Shitrit D, Atar E, Saute M, Shlomi D, et al. Use of Amplatzer device for endobronchial closure of bronchopleural fistulas. Chest. 2008;133: 1481-4.

4. Datau H, Breen DP, Gomez C, Thomas PA, Vergnon JM. The integrated place of tracheobronchial stents in the multidisciplinary management of large post-pneumonectomy fistulas: our experience using a novel customised conical self-expandable metallic stent. Eur J Cardiothorac Surg. 2011;39: $185-9$.

5. Andreetti C, D'Andrilli A, Ibrahim M, Rendina EA. Treatment of a complex tracheobronchial malignant stenosis with modified conical semicovered selfexpanding stent. J Thorac Cardiovasc Surg. 2013;146:488-9. 